\title{
Trend and status of out-of-pocket payments for healthcare in Iran: equity and catastrophic effect
}

\author{
Satar Rezaei ${ }^{1}$, Abraha Woldemichael $^{2}$, Mohammad Ebrahimi $^{3}$ and Sina Ahmadi ${ }^{*}$
}

\begin{abstract}
Background: Equity in the distribution of health care resources and mitigating the risk of out-of-pocket (OOP) catastrophic healthcare expenditures (CHE) are the major objectives of the health system of a country. This study aims to measure equity in OOP payments for healthcare and the incidence of CHE among Iranian households over time.

Methods: This retrospective cross-sectional study utilized data extracted from the household income and expenditure survey (HIES) of Iran, collected by the Statistical Center of Iran. The analysis included a total of 174,341 households' five yearly data of 6 years starting from 1991 to 2017. Kakwani progressivity index (KPI) was used to measure the equity in OOP payment for each year and examine the households' incidence of CHE at 20\%, 30\%, and $40 \%$ of their capacities to pay (CTP). The trend series regression analysis was used to examine the trend in the $\mathrm{KPI}$ and the incidence of the CHE over time.
\end{abstract}

Results: The findings indicated that the households' expenditure on health out of their monthly budgets for the years 1991 and 2017 were $2.1 \%$ and 10.1\%, respectively. The KPI for the OOP payment was negative for all 6-year observations $(1991=-0.680 ; 1996=-0.608 ; 2001=-0.554 ; 2006=-0.265 ; 2011=-0.225$, and $2017=-0.207)$, indicating that the OOP payments for healthcare are regressive and more concentrated among the socioeconomically disadvantaged households. There was a statistically significant $(p=0.003)$ increase in the KPI (i.e., decline in the regressivity) over time. The incidence of the CHE (1.12, 1.93, and 3.71\%) in 1991 at the CTP levels of $20 \%, 30 \%$, and $40 \%$ was lower than the incidence at the corresponding levels of CTP $(5.26,10.88$, and 22.16$)$ in 2017. The findings of the time-series regression indicated a statistically significant $(p<0.05)$ increase in the incidence of the CHE at the $20 \%, 30 \%$, and $40 \%$ levels of the households' CTP.

Conclusions: The current study demonstrated that OOP payment as a source of healthcare funding in Iran is inequitable. While the use of interventions such as the prepaid and publicly funded programs may contribute to the reduction of CHE and improvement of equity in healthcare financing, further inequality analyses in the incidence of the CHE among households and its main determinants can contribute to evidence-informed planning to reduce the $\mathrm{CHE}$ in the context.

Keywords: Financing personal, Health equity, Health disparities, Out-of-pocket payments, Health expenditure, Kakwani progressivity index, Catastrophic healthcare expenditure

\footnotetext{
*Correspondence: sinaahmadi25@gmail.com

${ }^{4}$ Department of Social Welfare Management, University of Social Welfare and Rehabilitation Sciences, Tehran, Iran

Full list of author information is available at the end of the article
}

\section{Springer Open}

(๑) The Author(s). 2020 Open Access This article is licensed under a Creative Commons Attribution 4.0 International License, which permits use, sharing, adaptation, distribution and reproduction in any medium or format, as long as you give appropriate credit to the original author(s) and the source, provide a link to the Creative Commons licence, and indicate if changes were made. The images or other third party material in this article are included in the article's Creative Commons licence, unless indicated otherwise in a credit line to the material. If material is not included in the article's Creative Commons licence and your intended use is not permitted by statutory regulation or exceeds the permitted use, you will need to obtain permission directly from the copyright holder. To view a copy of this licence, visit http://creativecommons.org/licenses/by/4.0/. 


\section{Introduction}

The concern for equity in healthcare financing is a common issue in many countries regardless of their socioeconomic development [1-3]. A health system is equitable if all people have fair access to healthcare, and if the people's ability to pay is not limiting their healthcare utilization. In healthcare, the perspective of equity study is either healthcare utilization or healthcare financing [4-6].

The sources to healthcare financing in many countries included general taxation, social health insurance, private health insurance, community financing, and out-ofpocket (OOP) payments [7]. In under-resourced countries like Iran, OOP healthcare financing is a major source of funding $[8,9]$. In Iran, the OOP payment accounted for more than $50 \%$ of the total healthcare expenditure of the country [10] which is higher than the values reported for other countries [11]. The high OOP payment for healthcare is likely to be associated with CHE and inequity of healthcare financing [12]. A study indicated that more than $5 \%$ of the Iranian households experienced $\mathrm{CHE}$, and the $\mathrm{CHE}$ was higher among those in lower socioeconomic status [13].

Households may suffer the consequences of OOP payments for two reasons. First, the direct OOP payment for the healthcare service at the time of service use can lead households to CHE. Second, the OOP payment for healthcare may be regressive. The unfair distribution of OOP payment for healthcare can negatively influence equity in healthcare financing, and this can be measured using the Kakwani progressivity index (KPI), which is one of the most commonly used methods $[9,14]$. An increase in households' OOP payment for healthcare services with an increase in income indicates a progressivity in OOP payment and an increase in OOP payment with a reduction in income shows a regressivity in OOP payment for healthcare [15]. In Iran, there is limited evidence on the trend of equity in healthcare financing. Few studies reported the existence of the inequity of healthcare financing. For example, one study reported a positive KPI and progressive OOP payments for healthcare for the urban residents and a negative KPI and regressive OOP for the rural ones [16]. Another study reported a negative $(-0.112)$ KPI for the healthcare costs (OOP payment for healthcare plus health insurance premiums) [17]. Besides, the KPI for general taxation and health insurance premiums were progressive and regressive, respectively [18].

Monitoring the equity of OOP payments for healthcare services and measuring the incidence of $\mathrm{CHE}$ among households over time are two main strategies to examine a health system's performance towards financial protection for citizens. This study aims to measure the equity in OOP payments for healthcare services and determine the incidence of CHE at the households' 20\%, $30 \%$, and $40 \%$ levels of CTP using five yearly national household survey data for 6 years. The findings of this study are anticipated to contribute valuable input for policymakers in Iran and other countries with similar contexts to ensure equity in healthcare financing and reducing CHE.

\section{Methods}

\subsection{Study setting}

Iran is a developing country, located in the Eastern Mediterranean Region (EMR) with 80 million population living across 31 provinces in urban (76\%) and rural (24\%) settings https://www.amar.org.ir/english/Population-and-Housing-Censuses.

\subsection{Study population, sampling method, data collection, and sample size}

This retrospective cross-sectional study was conducted using data extracted from the household income and expenditure surveys (HIESs) of Iran, which was collected annually by the Iranian Statistical Center (ISC) https:// www.amar.org.ir/english/Statistics-by-Topic/HouseholdExpenditure-and-Income\#2220530-releases. In summary, in the HIESs, the data was collected using a structured standard questionnaire for a face-to-face interview for the household head. All data in the HIES were collected for the past month before the survey from the households included in the survey. All the households living in the rural and urban areas of Iran were eligible to participate in the survey. A multistage cluster sampling technique was applied to obtain the sample. Finally, after excluding the observation with incomplete information, a total of 174,341 households for 6-year observations for the years $1991(n=18582), 1996(n=21854), 2001(n$ $=26714), 2006$ ( $n=31$ 111), $2011(n=38220)$, and 2017 ( $n=37860)$ were included in the study.

\subsection{Data and variables}

The household size and total monthly expenditure in the last month before the survey were the variables used for the analysis. We used the household expenditure on health as the total OOP payment for healthcare services, and the total expenditure (TE) as a proxy for the households' ability to pay $[6,19,20]$. The household expenditure is more advantageous than the household income because income is likely to be underreported and can vary over time $[19,20]$. As per previous studies and for the proper comparison $[6,21]$, we equivalized the households' TE and OOP payment by dividing the TE and OOP payment to the squared root of the household size. 


\subsection{Measuring progressivity in OOP payment for healthcare}

Like other previous studies [6, 22], we measured the KPI that was used to measure the equity in OOP payments for healthcare among Iranian households using five yearly data points of 6 years (1991, 1996, 2001, 2006, 2011, and 2017), and mathematically, this is expressed as follows $[22,23]$ :

$$
\mathrm{KPI}=C_{\mathrm{oop}}-G_{\mathrm{atp}}
$$

where KPI represents the Kakwani progressivity index, $C$ is the concentration index for the OOP payment for healthcare, and $G$ represents the Gini coefficient for the household's income.

The values of $C$ can range from -1 to +1 . The negative (positive) value indicates the concentration of the OOP payment in favor of the socioeconomically disadvantaged (advantaged) households, while the zero value indicates perfect equality. The $G$ values range from 0 to 1 , and the farther away the value from zero, the higher is the inequality. Generally, the $C(G)$ is twice the area between the concentration (Lorenz) curve and the line of perfect equality. The KPI values range from -2 to 1 . The negative KPI values for the OOP payment show the regressivity of the OOP payment for healthcare, indicating an inverse relationship between the OOP payment for healthcare and the household's income. That is, an increase in the households' income will be associated with a decrease in the OOP and vice versa. A positive KPI indicates the progressivity of the OOP payment for healthcare, suggesting the existence of equity in the OOP payments, and an association between the OOP payment for healthcare and households' income. If OOP payment is proportional to household's income, the KPI is zero $[6,16]$.

\subsection{Measuring catastrophic healthcare expenditure}

This study applied the World Health Organization's (WHO) standard approach to calculating the incidence of CHE at 20\%, 30\%, and $40 \%$ of the households' capacity to pay (CTP) https://www.amar.org.ir/ english/Population-and-Housing-Censuses. In this study, we described the CTP of the household as the difference between the households' total expenditure (TE) and the expenditures of food adjusted to household size [13, 19]. For example, at the $40 \%$ of the households' CTP, a household is considered in a state of $\mathrm{CHE}$ if the household's OOP payment is greater than or equal to $40 \%$ of its CTP. The more details of the calculation of $\mathrm{CHE}$ base on WHO approach are available elsewhere [24, 25].

\subsection{Trend analysis}

We conducted a 6-year time-series observation regression analysis for the KPIs and incidence of the CHE and presented the findings for the total, urban, and rural households. In addition, we performed a trend regression analysis of the incidence of CHE at 20\%,30\%, and $40 \%$ levels of the household's CTP separately. When the coefficient value is positive and its $p$ value is less than 0.05 , it indicates an increasing and statistically significant trend in progressivity (incidence of $\mathrm{CHE}$ ) over time and a negative value indicates a statistically significant decreasing trend.

\section{Results}

\subsection{Ability to pay and out-of-pocket payment for health care}

The mean equivalized households' TE and OOP for healthcare for the total, urban, and rural households in Iran for each year is summarized in Table 1. Overall, the mean equivalized TE of the households increased from 182,655 Iranian Rials (IRR) in 19991 to 10,313,116 IRR in 2017. Besides, the trend in households' TE of the total, urban, and rural households showed a statistically significant $(p<0.05)$ increase overtime. However, the mean equivalized TE for urban households was higher than the rural ones across the years. Despite the increasing trend in the mean equivalized OOP payment for healthcare for the total, urban, and rural households over time, the increasing trend was significant $(p=$ 0.036) for the total households.

The percentage of households' OOP payments for healthcare out of the TE for total, rural, and urban households is indicated in Fig. 1. The OOP payment for total households in 1991 accounted for $2.09 \%$ of the TE, while in 2017 it accounted for $10.61 \%$. Despite a considerable difference between the urban and rural households $(3.36 \%$ versus $1.35 \%)$ in the percentage of OPP payment for healthcare during 1991, there was no marked difference between the two (10.62 versus $10.59 \%)$ in 2017.

\subsection{Progressivity in out-of-pocket health expenditure}

The KPIs of the households' OOP payments for the total, urban, and rural households across the years were negative (Table 2), suggesting the regressivity of the OOP payment. That is, the households' OOP payment for healthcare relative to their CTP was not equitable, and there was an inverse relationship between the OOP payment for healthcare services and the TE of the households. The KPI for total households increased from - 0.680 in 1991 to -0.207 in 2017. The regression analysis of the KPIs time-series observations for the total, urban, and rural households showed statistically significant $(p<0.05)$ declining trends in the regressivity of the 
Table 1 Mean equivalized TE and OOP payment for health care of the total, urban, and rural households over 6 years in Iran

\begin{tabular}{llll}
\hline Survey year & $\begin{array}{l}\text { Mean E.TE } \\
\text { total (SD) }\end{array}$ & $\begin{array}{l}\text { Mean E.TE } \\
\text { urban (SD) }\end{array}$ & $\begin{array}{l}\text { Mean E.TE } \\
\text { rural (SD) }\end{array}$ \\
\hline 1991 & $182,655(473,718)$ & $137,687(588,989)$ & $226,166(306,352)$ \\
1996 & $362,793(370,750)$ & $469,789(447,086)$ & $255,600(227,952)$ \\
2001 & $997,484(1,469,453)$ & $1,332,746(1,967,313)$ & $710,833(719,879)$ \\
2006 & $2,453,703(3,042,291)$ & $3,161,533(326,331)$ & $1,843,366(3,793,022)$ \\
2011 & $5,300,166(5,115,093)$ & $6,186,995(4,116,561)$ & $4,464,271(5,866,648)$ \\
2017 & $10,313,116(8,955,380)$ & $12,927,756(6,392,161)$ & $7,773,356(1,040,000)$ \\
Trend coefficients $(p$ value) & $1,912,018(0.012)$ & $2,285,321(0.040)$ & $1,471,271(0.011)$ \\
Survey year & Mean E.OOP payment for & Mean E.0OP payment for & Mean E.oOP payment for \\
& healthcare total (SD) & healthcare urban (SD) & healthcare rural (SD) \\
1991 & $3825(24,939)$ & $4632(29,528)$ & $3044(19,465)$ \\
1996 & $17,673(93,656)$ & $22,382(110,431)$ & $12,956(72,786)$ \\
2001 & $59,020(548,010)$ & $80,580(791,694)$ & $40,586(143,075)$ \\
2006 & $165,244(426,211)$ & $217,035(2,006,705)$ & $120,585(492,108)$ \\
2011 & $362,151(675,707)$ & $436,793(789,606)$ & $291,796(537,671)$ \\
2017 & $1,094,500(2,070,867)$ & $1,373,426(2,374,534)$ & $823,561(1,681,805)$ \\
Trend coefficients $(p$ value) & $188,372.3(0.036)$ & $319,090(0.337)$ & $143,403(0.330)$ \\
\hline
\end{tabular}

$E$ equivalized, $S D$ standard deviation, $T E$ total expenditure, OOP out-of-pocket

households' OOP payments, and the three coefficients were nearly equal.

\subsection{Catastrophic healthcare expenditure}

The incidence of the CHE for total, urban, and rural households at $20 \%, 30 \%$, and $40 \%$ levels of their CTP is presented in Table 3. At the $40 \%$ level of threshold of household CTP, the incidence of CHE for the total, urban, and rural households in 1991 were 1.12, 1.15, and $1.09 \%$, respectively. The figures for the corresponding categories in 2017 were 5.26, 4.02, and $6.47 \%$ in 2017, respectively. The time-series regression of incidence of CHE for total, urban, and rural households at the $40 \%$ level of the CTP revealed a statistically insignificant $(p>$ 0.05 ) increasing trend in the incidence. At the $30 \%$ level CTP, the trend for the CHE was statistically insignificant ( $p=0.136)$ only for urban households, while at the $20 \%$ level, the trends for all three categories increased significantly $(p<0.05)$ over time.

\section{Discussion}

The current study indicated that the households' expenditure on health out of their monthly budgets for the years 1991 and 2017 increased 5 times in Iran. The KPI for the OOP payment was negative for all 6-year observations, indicating that the OOP payments for healthcare are regressive and more concentrated among the socioeconomically disadvantaged households. There was a statistically significant increase in the KPI (i.e., decline in the regressivity) over time. The incidence of the CHE in 1991 at the CTP levels of $20 \%, 30 \%$, and $40 \%$ was lower than the incidence at the corresponding levels of CTP in 2017. The findings of the time-series regression indicated a statistically significant increase in the incidence of the CHE at the different levels of the households' CTP.

The use of income as a proxy for the households' ability to pay is not appropriate because income varies from time to time and tends to overestimate the households' expenditures $[6,19,20]$. Our study applied the total expenditure in determining the ability to pay of the household. The findings indicated an increasing trend in the OOP payment for healthcare over time. Another study in Western Iran also reported a higher expenditure (5\% versus 9\%) in 1991 and in 2011 [26].

Our findings also indicated negative coefficients of the KPIs for the OOP payment for healthcare across the years and the categories, indicating the regressivity of the households' OOP payments for healthcare services. These findings are consistent with the reports of other several studies $[6,16-18,27]$. Another study in Africa also reported a negative coefficient $(\mathrm{KPI}=-0.20)$ of the OOP for healthcare [28]. The regressivity of OOP payment for healthcare indicates that the OOP payment is not related to the households' income. Similarly, another study in Ghana indicated regressivity for the OOP payment for healthcare and progressivity for taxation [29]. The different reforms in the health sector of Iran as the urban inpatient health insurance plan, the rural health insurance scheme, and the health sector evolution plan, which were introduced in 2001, 2005, and 2014, respectively might have contributed to the reduction in 

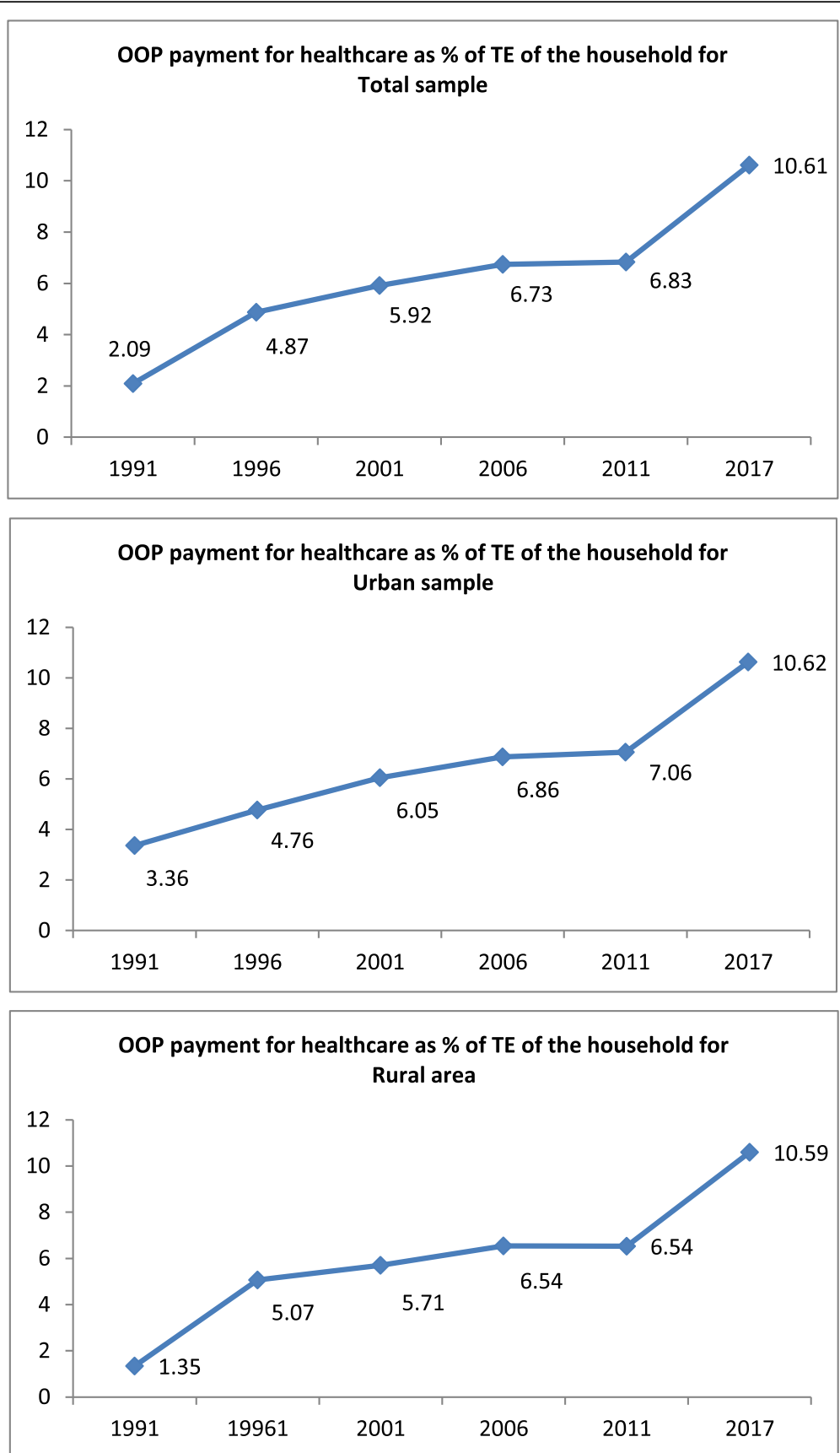

Fig. 1 Trend in OOP payment for healthcare services as percentage of the households' CTP for the total, urban, and rural households over six years in Iran. Note: TE refers total expenditure

regressivity of the households' OOP payments for healthcare services observed in our findings.

The incidence of CHE observed in our findings not only was high but also showed an increasing trend over time. Our findings indicated higher overall CHE than the findings of another study report [13]. The high CHE observed in our findings regardless of the residence of the households affects fair utilization of healthcare services among citizens, especially the disadvantaged groups, and threatens the achievement of sustainable health development goals for health in Iran. This situation calls for an effective health policy and an intersectoral effort to improve the socioeconomic status of the citizens to protect them against $\mathrm{CHE}$ and its negative consequences. 
Table 2 KPIs for total, urban, and rural households over 6 years in Iran

\begin{tabular}{llll}
\hline Survey year & KPIs for total households & KPIs for urban & KPIs for rural \\
\hline 1991 & -0.680 & -0.560 & -0.741 \\
1996 & -0.608 & -0.600 & -0.544 \\
2001 & -0.554 & -0.586 & -0.442 \\
2006 & -0.265 & -0.199 & -0.319 \\
2011 & -0.225 & -0.219 & -0.209 \\
2017 & -0.207 & -0.189 & -0.165 \\
Trend coefficients $(p$ value) & $0.1086(0.003)$ & $0.967(0.025)$ & $0.1144(0.001)$ \\
\hline
\end{tabular}

KPIs Kakwani progressivity index

The difference observed in the incidence of the CHE among the urban and rural households observed in our study are almost consistent with the findings of several studies [2, 12, 30, 31]. The higher incidence of CHE among rural residents may imply poorer socioeconomic status of the rural households than the urban ones. Other researchers also reported that the OOP payments for healthcare led the poor rural people to be poorer than urban residents [30]. Unlike the findings in our study, independent studies in Portugal [32] and Canada
[6] revealed a reducing trend in the incidence of $\mathrm{CHE}$ over time.

\subsection{Strengths and limitations of the study}

Unlike previous studies in Iran based on 1-year data [18] or for a single province [17], our study analyzed the equity in OOP payments for healthcare services and its catastrophic incidence using 6-year annual data points representing the whole Iran and also using WHO standard approach. The overall picture of the total, urban,

Table 3 Incidence of CHE at the three different levels of the CTP of the households for total, urban, and rural areas over 6 years in Iran

\begin{tabular}{|c|c|c|c|c|}
\hline Survey year & & CHE for total & CHE for urban & CHE for rural \\
\hline \multirow[t]{3}{*}{1991} & $40 \%$ thresholds & 1.12 & 1.15 & 1.09 \\
\hline & $30 \%$ thresholds & 1.93 & 1.98 & 1.88 \\
\hline & $20 \%$ thresholds & 3.71 & 3.91 & 3.53 \\
\hline \multirow[t]{3}{*}{1996} & $40 \%$ thresholds & 2.42 & 1.93 & 2.91 \\
\hline & $30 \%$ thresholds & 3.98 & 3.18 & 4.77 \\
\hline & $20 \%$ thresholds & 7.38 & 5.69 & 9.07 \\
\hline \multirow[t]{3}{*}{2001} & $40 \%$ thresholds & 4.08 & 4.09 & 4.07 \\
\hline & $30 \%$ thresholds & 6.75 & 6.54 & 6.96 \\
\hline & $20 \%$ thresholds & 13.04 & 12.40 & 13.67 \\
\hline \multirow[t]{3}{*}{2006} & $40 \%$ thresholds & 1.75 & 1.33 & 2.11 \\
\hline & $30 \%$ thresholds & 3.72 & 1.08 & 6.00 \\
\hline & $20 \%$ thresholds & 10.48 & 9.17 & 11.61 \\
\hline \multirow[t]{3}{*}{2011} & $40 \%$ thresholds & 3.38 & 3.76 & 3.03 \\
\hline & $30 \%$ thresholds & 6.43 & 6.85 & 6.04 \\
\hline & $20 \%$ thresholds & 13.86 & 14.77 & 13.01 \\
\hline \multirow[t]{3}{*}{2017} & $40 \%$ thresholds & 5.26 & 4.02 & 6.47 \\
\hline & $30 \%$ thresholds & 10.88 & 8.63 & 13.07 \\
\hline & $20 \%$ thresholds & 22.16 & 19.49 & 24.76 \\
\hline \multirow[t]{3}{*}{ Trend coefficients ( $p$ value) } & $40 \%$ thresholds & $0.607(0.094)$ & $0.488(0.157)$ & $0.723(0.100)$ \\
\hline & $30 \%$ thresholds & $1.402(0.039)$ & $1.10(0.136)$ & $1.06(0.032)$ \\
\hline & $20 \%$ thresholds & $3.118(0.009)$ & $2.91(0.006)$ & $3.31(0.019)$ \\
\hline
\end{tabular}


and rural households' OOP payments and the incidence of the CHE at different levels of the CTP over time shed light to understand the effectiveness of existing policies in the context. Thus, the findings provided an important input for policy makers to make appropriate reforms to increase citizens' financial protection against $\mathrm{CHE}$ in Iran. However, this study has some limitations. The household income and expenditure survey (HIES) data are self-reported and represent only the households' OOP payment for healthcare of the past 1 month of the date of data collection, and it is prone to recall bias. Besides, this study did not analyze the equity status among households in relation to other sources of healthcare financing such as the general taxation and health insurance premiums because of the lack of data concerning these financing sources.

\section{Conclusions}

Measuring the extent and trends of households' OOP payment for healthcare services and CHE helps tracking the effect of existing health policies in reducing inequity in healthcare access to people. This study analyzed the progressivity/regressivity of OOP payments for healthcare services among Iranian households in relation to their income. The findings indicated increasing trends and considerably high incidence of CHE over time, implying the need for policymakers to pay emphasis to the citizens' financial protection against CHE in order to ensure progress toward achieving the universal health coverage target of the sustainable development goals for health. While the use of policies such as the prepaid and publicly funded schemes may contribute to the reduction of high CHE and in improving equity in healthcare financing, further inequality analyses in the incidence of the CHE among households and its main determinants can contribute to evidence-informed planning to reduce the CHE in the context.

\section{Abbreviations}

CHE: Catastrophic healthcare expenditure; TE: Total expenditure; CTP: Capacity to pay; KPI: Kakwani progressivity index; HIES: Households' income and expenditure survey

\section{Acknowledgements}

The authors wish to thank Dr. Behzad Karami Matin from Kermanshah University of Medical Sciences for his help to conduct this study.

\section{Authors' contributions}

All authors contributed to the conception and design of the study. SR and SA performed the data analysis. SR, AWM, and ME drafted the manuscript. All authors read and approved the final manuscript.

\section{Funding}

This study was supported and funded by Kermanshah University of Medical Sciences (code number 990005). The Funder had no role in the design of the study and collection, analysis, and interpretation of data and in writing the manuscript.

\section{Availability of data and materials}

The data used in the study was extracted from the household income and expenditure surveys (HIESs) collected by the Iranian Statistical Center (ISC). The HIES are publicly available at https://www.amar.org.ir/english/Statisticsby-Topic/Household-Expenditure-and-Income\#2220530-releases.

\section{Ethics approval and consent to participate}

The study was approved by the Ethics Review Committee (ERC) of the Deputy of Research at Kermanshah University of Medical Sciences (IR.KUMS.REC.1399.000). Consent to participate is not applicable.

\section{Consent for publication}

Not applicable.

\section{Competing interests}

The authors declare that there are no competing interests.

\section{Author details}

${ }^{1}$ Research Center for Environmental Determinants of Health, Health Institute, Kermanshah University of Medical Sciences, Kermanshah, Iran. ${ }^{2}$ Department of Health Systems, School of Public Health, College of Health Sciences, Mekelle University, Tigray, Ethiopia. ${ }^{3}$ Student Research Committee, Kermanshah University of Medical Sciences, Kermanshah, Iran. ${ }^{4}$ Department of Social Welfare Management, University of Social Welfare and Rehabilitation Sciences, Tehran, Iran.

Received: 21 December 2019 Accepted: 3 September 2020

Published online: 03 November 2020

\section{References}

1. Sparkes SP, Bump JB, Özçelik EA, Kutzin J, Reich MR. Political economy analysis for health financing reform. Health Syst Reform. 2019;5(3):183-94.

2. Aryankhesal A, Etemadi M, Mohseni M, Azami-Aghdash S, Nakhaei M. Catastrophic health expenditure in Iran: a review article. Iran J Public Health. 2018:47(2):166-77.

3. Culyer AJ, Wagstaff A. Equity and equality in health and health care. J Health Econ. 1993;12(4):431-57.

4. Chowdhury S, Gupta I, Trivedi M, Prinja S. Inequity \& burden of out-ofpocket health spending: district level evidences from India. Indian J Med Res. 2018;148(2):180-9.

5. Achoki T, Lesego A. The imperative for systems thinking to promote access to medicines, efficient delivery, and cost-effectiveness when implementing health financing reforms: a qualitative study. Int J Equity Health. 2017;16(1): 53.

6. Edmonds S, Hajizadeh M. Assessing progressivity and catastrophic effect of out-of-pocket payments for healthcare in Canada: 2010-2015. Eur J Health Econ. 2019;20(7):1001-11.

7. Gottret $\mathrm{P}, \mathrm{Schieber} \mathrm{G}$. Health financing revisited: a practitioner's quide: The World Bank; 2006

8. Chu A, Kwon S, Cowley P. Health financing reforms for moving towards universal health coverage in the western pacific region. Health Sys Ref. 2019;5(1):32-47.

9. Fakhri M, Juni MH, Rosliza AM. Assesing progressivity of out-of-pocket expenditures for health care: evidence from households in Malaysia. Int J Public Health Clin Sci. 2019;6(3):187-202.

10. Khosravi B, Soltani S, Javan-Noughabi J, Faramarzi A. Health care expenditure in the Islamic Republic of Iran versus other high spending countries. Med J Islam Repub Iran. 2017;31:71.

11. WHO. World health statistics 2016: monitoring health for the SDGs sustainable development goals. Geneva: World Health Organization; 2016.

12. Hailemichael Y, Hanlon C, Tirfessa K, Docrat S, Alem A, Medhin G, et al. Catastrophic health expenditure and impoverishment in households of persons with depression: a cross-sectional, comparative study in rural Ethiopia. BMC Public Health. 2019;19(1):930.

13. Rezaei S, Hajizadeh M. Measuring and decomposing socioeconomic inequality in catastrophic healthcare expenditures in Iran. J Prev Med Public Health. 2019;52(4):214.

14. Wagstaff A. Measuring financial protection in health. Washington, DC: World Bank; 2008. 
15. Hajizadeh M, Connelly LB, Butler JRG. Health policy and equity of health care financing in Australia: 1973-2010. Rev Income Wealth. 2014;60(2):298322.

16. Almasiankia A, Kavosi Z, Keshtkaran A, Jafari A, Goodarzi S. Equity in health care financing among Iranian households. Shiraz E-Medical Journal. 2015; 16(11-12).

17. Jalali FS, Jafari A, Bayati M, Bastani P, Ravangard R. Equity in healthcare financing: a case of Iran. Int J Equity Health. 2019;18(1):92.

18. Homaei Rad E, Khodaparast M. Inequity in health care financing in Iran: progressive or regressive mechanism? Eurasian J M. 2016;48(2):112.

19. Xu K, Evans DB, Kawabata K, Zeramdini R, Klavus J, Murray CJ. Household catastrophic health expenditure: a multicountry analysis. The lancet. 2003; 362(9378):111-7.

20. O'donnell O, Van Doorslaer E, Wagstaff A, Lindelow M. Analyzing health equity using household survey data: a guide to techniques and their implementation. Washington, DC: The World Bank; 2007.

21. Wagstaff A, Ev D. Catastrophe and impoverishment in paying for health care: with applications to Vietnam 1993-1998. Health Econ. 2003;12(11):921-33.

22. Kakwani NC. Measurement of tax progressivity: an international comparison. Econ J. 1977;87(345):71-80

23. Wagstaff A, Van Doorslaer E, Van der Burg H, Calonge S, Christiansen T, Citoni $\mathrm{G}$, et al. Equity in the finance of health care: some further international comparisons. J Health Econ. 1999;18(3):263-90.

24. Yardim MS, Cilingiroglu N, Yardim N. Catastrophic health expenditure and impoverishment in Turkey. Health Policy. 2010;94(1):26-33.

25. Xu K, World Health Organization. Distribution of health payments and catastrophic expenditures methodology. Geneva: World Health Organization; 2005

26. Limwattananon S, Tangcharoensathien V, Prakongsai P. Catastrophic and poverty impacts of health payments: results from national household surveys in Thailand. Bull World Health Organ. 2007;85(8):600-6.

27. Molla AA, Chi C. Who pays for healthcare in Bangladesh? An analysis of progressivity in health systems financing. Int J Equity Health. 2017;16(1):167.

28. Cissé B, Luchini S, Moatti JP. Progressivity and horizontal equity in health care finance and delivery: what about Africa? Health Policy. 2007:80(1):51-68,

29. Akazili J, Gyapong J, McIntyre D. Who pays for health care in Ghana? Int J Equity Health. 2011:10(1):26.

30. Qosaj FA, Froeschl G, Berisha M, Bellaqa B, Holle R. Catastrophic expenditures and impoverishment due to out-of-pocket health payments in Kosovo. Cost Eff Resour Alloc. 2018;16(1):26.

31. Aregbeshola BS, Khan SM. Out-of-pocket payments, catastrophic health expenditure and poverty among households in Nigeria 2010. Int J Health Policy Manag. 2018;7(9):798.

32. Quintal C. Evolution of catastrophic health expenditure in a high income country: incidence versus inequalities. Int J Equity Health. 2019;18(1):145.

\section{Publisher's Note}

Springer Nature remains neutral with regard to jurisdictional claims in published maps and institutional affiliations.

\section{Submit your manuscript to a SpringerOpen ${ }^{\circ}$ journal and benefit from:}

- Convenient online submission

- Rigorous peer review

- Open access: articles freely available online

- High visibility within the field

- Retaining the copyright to your article

Submit your next manuscript at $\boldsymbol{\nabla}$ springeropen.com 